\title{
Targeting unprofessionalism among Medical Students in Indian settings
}

\author{
Shrivastava, S.R. ${ }^{1}$ \& Shrivastava, P.S. ${ }^{2}$
}

\section{Introduction}

Professionalism has been identified as one of the core competencies, which a medical undergraduate student, postgraduate resident, a physician and teaching faculty should acquire by most of the medical councils across the world, including the Medical Council of India (Franco et al., 2015).

For time immemorial, doctors have been regarded as "professionals" both by the public and by their peers, and thus they were regarded as the most trusted profession among the general public (Franco et al., 2015). However, the scenario has changed big time in the current set-up and doctors are no more looked upon as the healers (McGoldrick, 2016). This is because, we, as the doctor community have failed to sustain the standard which was set by our earlier professionals and thus we have to pay the price for the same (McGoldrick, 2016; Binder et al., 2015).

\footnotetext{
'Vice Principal Curriculum, Member of the Medical Education Unit \& Institute Research Council, Associate Professor, Department of Community Medicine, Shri Sathya Sai Medical College \& Research Institute, Kancheepuram, Sri Balaji Vidyapeeth, India
}

${ }^{2}$ Associate Professor, Department of Community Medicine, Shri Sathya Sai Medical College \& Research Institute, Kancheepuram, Sri Balaji Vidyapeeth, India

Corresponding Author:

Dr. Saurabh RamBihariLal Shrivastava

3rd floor, Department of Community Medicine, Shri Sathya Sai Medical College \& Research Institute, Ammapettai village, Thiruporur - Guduvancherry Main Road, Sembakkam Post, Kancheepuram - 603108, Tamil Nadu, India

Email:drshrishri2008@gmail.com

\section{Unprofessionalism and its consequences}

The unprofessional behaviors of medical fraternity can range from lack of respect towards seniors or juniors or even towards patients \& caregivers, use of inappropriate language and sub-standard behavior, poor communication skills, abuse of team members or patients, prescribing unnecessary medications or investigations, etc (McGoldrick, 2016; Binder et al., 2015). In the current clinical practice, the effect of our unprofessional approach has featured in various ways, like one doctor does not trust another and keep criticizing each other in front of patients, which has led to lack of trust among people towards the doctor community (McGoldrick, 2016).

Moreover, there is a definite increase in the incidence of assault against doctors and vandalization of hospital property, publicly criticized for cut-practice by many stakeholders $\&$ that has affected our reputation big time and people have continued with their belief on traditional healers instead of seeking help of the modern medicine specialists (McGoldrick, 2016; Binder et al., 2015). In addition, we are looked upon as the money minded people and each and every action of us (in terms of ordering even basic investigations, etc.) raises eyebrows and we have lost the respect even from our team members (nurses, paramedical staff), predominantly due to the unethical practices adopted by some of the doctors. Finally, there is no unity among doctors on any issue and thus we fail to stand together even for the right issue.

\section{Detection of unprofessional behavior}

A good way to identify any unprofessional behavior can be through keeping a "Suggestion Box" in each of the healthcare settings, where people (including the health staff) can share 
their bad experiences anonymously or through exit interviews. Now a day's, surveillance cameras have been installed in many health care establishments, which can also aid in the identification of unprofessional behaviors.

\section{Proposed solutions}

However, the above mentioned measures cannot be looked upon as a long-term solution, instead steps have to be taken to inculcate the behavior of professionalism among future budding doctors and medical college fraternity, through approaches like:

- All the faculty members working in a medical college set-up are being mandated to get trained in the Revised Basic Course and Attitude \& Communication module, both of which emphasize the importance of professionalism. These training sessions not only motivate the faculty members to have a professional approach, but also to pass on the same to the undergraduate as well as postgraduate students

- Medical Educators have been working upon to introduce ethics and professionalism in the existing curriculum, without expanding the duration of the under-graduation course

- Adoption of the Competency Driven Curriculum and that will be a benchmark step to inculcate professionalism among the future budding doctors

- Role Modelling: It is one of the best ways to ensure that the tomorrow's doctor adheres to professional behaviors by observing their teachers (faculty members)

- Reflective writing: Each and every undergraduate student should be motivated to write reflections on their daily behaviors/interactions and that will be one of the most effective ways to teach them about professionalism. In-fact, they will learn professionalism on their own

- Feedback: Student can be given feedback about their interactions with the patients and how they can improve their professional behavior
- Assessment: Various tools for Work Place Based Assessment assesses the professional aspect of a clinical encounter and student can be made aware where she/he is weak professionally and how we can bridge the gap together

- Debriefing at the end of the clinical encounter (Franco et al., 2015; Abdel-Razig et al., 2016; Levey, 2015)

However, we should understand that it will be a time consuming process and we have to invest a lot to improve the professional behavior and regain the respect in the eyes of the general population (Franco et al., 2015; Abdel-Razig et al., 2016; Levey, 2015).

\section{Conclusion}

In conclusion, the medical profession has been plagued by unprofessionalism and it is high time that urgent \& targeted interventions are taken to improve the professionalism attributes among medical students.

\section{References}

Abdel-Razig, S., Ibrahim, H., Alameri, H., Hamdy, H., Haleeqa, K.A., Qayed, K.I., Obaid, L.O., Al Fahim, M., Ezimokhai, M., Sulaiman, N.D., Fares, S., Al Darei, M.M., Shahin, N.Q., Al Shamsi, N.A., Alnooryani, R.A. \& Al Falahi, S.Z. (2016) Creating a framework for medical professionalism: An initial consensus statement from an Arab Nation, Journal of Graduate Medical Education, 8, 2, pp. 165-172

Binder, R., Friedli, A. \& Fuentes-Afflick, E. (2015) Preventing and managing unprofessionalism in medical school faculties, Academic Medicine, 90, 4, pp. $442-446$

Franco, R.S., Franco, C.A., Severo, M. \& Ferreira, M.A. (2015) General competences on medical professionalism: Is it possible? Medical Teacher, 37, 10, pp. 976-977

Levey, N.N. (2015) Medical professionalism and the future of public trust in physicians, Journal of the American Medical Association, 313, 18, pp. 1827-1828

McGoldrick, K.E. (2016) Jarring Unprofessionalism: Argot Revisited, Journal of Graduate Medical Education, 8, 3, pp. 471-472 